Physical Disabilities: Education and Related Services, 2014, 33(1), 1-16. doi: 10.14434/pders.v33i1.4825

(C) Division for Physical, Health and Multiple Disabilities

\title{
PDERS
}

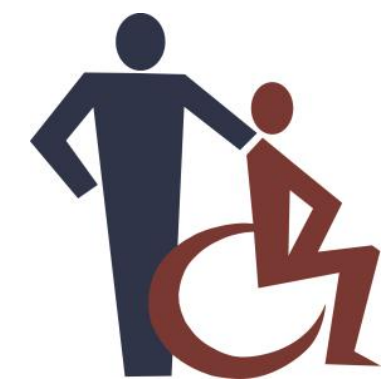

ISSN: 2372-451X

http://scholarworks.iu.edu/journals/index.php/pders/index

Article

\section{EARLY EXPOSURE TO PEOPLE WITH PHYSICAL AND SENSORY DISABILITIES AND LATER ATTITUDES TOWARD SOCIAL INTERACTIONS AND INCLUSION}

\author{
Emily M. Lund \\ Utah State University, University of Montana Rural Institute \\ Tom Seekins \\ University of Montana Rural Institute
}

\begin{abstract}
This study assessed the relationship between exposure to classmates with visible impairments in primary and secondary schools with later attitudes toward people with disabilities. Fifty college students (mean age $=20.28$ years; $76 \%$ female) completed measures assessing the extent and quality of recalled exposure to classmates with disabilities in elementary and secondary school. Attitudes toward social inclusion and toward a hypothetical social interaction were also measured. Participants reported generally high levels and quality of exposure, with significantly more exposure at the secondary level. Quality of exposure at both the elementary and secondary levels was significantly $(\mathrm{p}<.01)$ correlated with more positive cognitions (i.e., thoughts) during a hypothetical social interaction. Cognitions were not significantly correlated with emotions or behaviors, and amount of elementary exposure was negatively correlated with attitudes to social inclusion $(\mathrm{p}<.05)$. These results suggest a possible relation between positive early experiences and later friendship intentions that should be further explored.
\end{abstract}

Keywords: physical impairments; sensory impairments; young adults; inclusion; peers 


\section{Introduction}

American special education laws (e.g., Individuals with Disabilities Education Improvement Act [IDEIA], 2004) have long mandated student placement in the least restrictive environment. This requirement is based on the philosophy that students with disabilities should be educated among their non-disabled peers to the greatest extent appropriate. In other words, each child with a disability should be placed in the most inclusive educational environment that can provide the child with a satisfactory and meaningful educational experience. Theoretically, placement in the least restrictive environment promotes integration of and interaction among students with and without disabilities and provides students with disabilities a greater breadth of academic and social opportunities (United States Department of Education, n.d.). However, relatively little research has been conducted on the long-term outcomes of such integration on students without disabilities and their later attitudes toward people with disabilities.

\section{Social Exposure and Attitudes Toward Disability}

\section{Children}

In previous research (Diamond \& Hestenes, 1996), children as young as 3 and 4 years old have demonstrated the ability to identify the presence of physical or sensory impairments in photographs of other children. They were also able to discriminate among different categories of impairment but less able to detect less visible impairments, such as Down syndrome (Diamond $\&$ Hestenes, 1996). This suggests that physical or sensory impairments may form the cognitive representation of disability in young children. Additionally, the same study found that children did not rate children with physical or sensory impairments significantly lower on social desirability than children without obvious impairments. However, the children also tended to attribute the cause of the impairment to the environment, viewing it as the result of an external stimulus. For example, they may believe that a child with a walker is unable to walk because of a mobility aid, rather than realizing that the walker is used to ameliorate the effects of a disabling condition.

To control for this potential confound, Cameron, Rutland, and Brown (2007) created a study in which older children (ages 6 through 9) were given age-appropriate explanations of the nature of both physical and intellectual disabilities, including an emphasis on their usual permanency. The participants were placed in one of three groups: (a) an extended contact group in which they were read age-appropriate stories about children with disabilities, (b) a multiple classification group in which participants sorted pictures of children by both disability-related and nondisability-related characteristics, or (c) a control group that received no intervention. Participants in all three groups started with and maintained relatively positive attitudes toward children with both intellectual impairments and those with physical impairments. However, only the extended contact experimental condition showed significant post-intervention increases in positive attitudes toward disability and behavioral intentions toward people with impairments. 


\section{Adolescents}

Fisher, Pumpian, and Sax (1998) assessed the attitudinal differences toward people with disabilities in a high school that included students with disabilities and a demographically similar high school that did not. Although the researchers found no significant differences between the students at the two schools in terms of behavioral and social intentions toward students with disabilities, they did find that students in the integrated high school had less negative attitudes regarding the inclusion of students with severe disabilities in general education classes. Qualitative comments regarding students' experiences in integrated classes were generally positive.

Wong (2008) examined the effects of inclusive classrooms and peer interaction programs on the attitudes of students aged 13 to 17 in Hong Kong. Although the structured peer interaction program did create a similar increase in positive attitudes, inclusive education at the classroom level alone did not produce significant changes in the students' attitudes toward people with disabilities. However, it should be noted that the low percentage of students with disabilities in the school (less than $2 \%$ ) may have diluted the effects of the exposure.

In the realm of social exposure, Hastings, Sjöström, and Stevenage (1998) found a small but significant relationship between contact with people with disabilities in general and positive attitudes toward their inclusion in daily life and leisure activities. This held true for both inclusion of people with intellectual impairment and inclusion of people with speech impairment. However, when comparing scores of English and Swedish adolescents, Hastings and colleagues found a significant difference in attitudes between countries, suggesting that cultural factors may also play a role in shaping attitudes toward people with disabilities.

\section{Attitudes and Behavioral Intentions}

Despite the seemingly promising links between exposure and attitudes, there is some evidence that positive attitudes toward disability in general may not actually translate into positive, socially inclusive behavior toward children with disabilities. Laws and Kelly (2005) found that a significant number of children who were classified as having average to positive attitudes toward children with physical impairments nevertheless did not have inclusive behavioral intentions toward a hypothetical child with a physical impairment. This suggests that studies should measure specific behavioral intentions as well as general attitudes. Similarly, researchers have criticized traditional assessments of attitudes toward disability for being overly susceptible to social desirability bias (i.e., the perceived social pressure to report positive attitudes towards disability; Pruett \& Chan, 2006) and have developed alternatives, such as implicit attitudes tests (Pruett \& Chan, 2006) and measures of reactions to a hypothetical social situation (e.g., the Multidimensional Attitudes Scale [MAS]; Findler, Vilchinsky \& Werner, 2007).

\section{Long-Term Correlates of Exposure}

There is a dearth of information on the lasting, non-immediate correlates or effects of exposure to people with disabilities. In one of the few studies on the topic, Kishi and Meyer (1994) examined the attitudes of students between the ages of 15 and 19 who had been in Hawaii public 
schools when the state began mainstreaming students with disabilities in the late 1970s. They compared attitudes among students who were (a) enrolled in non-inclusive schools, (b) enrolled in non-inclusive schools ("exposure"), or (c) had participated in special programs designed to facilitate social interaction between students with and without disabilities ("contact"). Kishi and Meyer found that students who had been in inclusive schools or in special programs designed to facilitate interactions between students with and without disabilities generally reported more positive attitudes toward people with disabilities than those who were in non-inclusive schools. However, the students who went to inclusive ("exposure") schools did not have students with disabilities in their actual classes and were, therefore, only exposed to students with disabilities incidentally. Additionally, only structured interactions with students with severe disabilities were considered as "contact." Post-high school attitudes were not measured.

\section{Aim of the Present Study}

The aim of the present study was to examine the relationship between the attitudes of college students toward people with disabilities and their pre-college exposure to classmates with physical or sensory impairments during their elementary and secondary education. We chose to focus on physical and sensory impairments specifically because they can be easily recognized by even young children (Diamond \& Hestenes, 1996) and are likely to be memorable due to their visibility and relatively low incidence. It is possible that many elementary school-age children may not be able to recognize learning disabilities, mild intellectual disabilities, or emotional disorders as disabilities and thus would not recall those students as being disabled in hindsight, even if they qualified as such under IDEIA (2004).

The research questions were as follows:

1. Among a sample of college students without disabilities, how much exposure to classmates with physical and sensory disabilities in elementary and secondary education was recalled? What was the recalled quality of interactions with classmates with disabilities?

2. How did recalled exposure and quality of interaction relate to current attitudes toward social inclusion and social interaction with people with physical and sensory disabilities?

\section{Methods}

\section{Participants}

The participants in this study were drawn from a pool of students enrolled in Introduction to Psychology at a public university in the northwestern United States during the fall semester of 2009. Students taking Introduction to Psychology were required to participate in or review research as a course requirement. Students choosing to participate in this study were awarded two of the required eight research credits for participation.

Participants who self-identified as having a disability were excluded from the sample, as the purpose of the study was to assess the effects of interaction with people with physical or sensory impairments on the attitudes of students without disabilities. Participants who attended an elementary or secondary school in a non-American school system were also excluded from the 
study. Data from participants who answered one or both of these screening questions affirmatively were not included in the final analyses, but the students still received full credit for their participation.

A total of 51 participants initially volunteered to participate in the study. Complete MAS scores were missing for two participants, one of whom was also missing complete Social Inclusion Scale scores. The data from the participant who was missing both Social Inclusion Scale and MAS scores were excluded from data analyses resulting in a final sample size of 50 for analyses not involving the MAS. The second participant was missing complete MAS data; thus, the sample size for analyses involving the MAS was 49. The sample was majority female (76\%), of traditional college age $(M=20.28$ years, $S D=3.74$, range $=18-38$ years, $86 \%$ aged $18-22)$, and composed primarily of college freshmen $(50 \%)$ and sophomores $(32 \%)$. Although racial and ethnic data were not collected, the majority of students who attended the university were Caucasian.

\section{Measures and Scoring}

Recalled exposure. The Disability Exposure Scale was created by the authors for the purposes of this study. Four questions measured recalled frequency and perceived quality of classroom exposure to people with physical or sensory impairments across elementary school (grades K through 6) and junior high school and high school ("secondary school;" grades 7 through 12). Each question asked if the participant had any students with physical or sensory disabilities in his or her [grade-level] classes and used a response scale consisting of five possible answers. The possible answers and their values were "Yes, several" (4), "Yes, one or two" (3), "No, but there were students with other disabilities" (2), "No, to my knowledge, there were no students with disabilities" (0), and "Do not recall" (0). Because non-recalled experiences could not be quantitatively approximated, they were also coded as zero. However, there were no "Do not recall" responses in the present study. Examples of physical, sensory, and other impairments were provided on the questionnaire. Participants were then asked to rate the overall recalled quality of those interactions on a 7-point Likert-type scale, ranging from "extremely negative" (scored at -4) to "extremely positive" (scored at 4). Refer to Appendix A for the complete Disability Exposure Scale.

It should be noted that the item for elementary school exposure (1a) mistakenly read "junior high school classes (grades kindergarten through $6^{\text {th }}$ )" rather than "elementary school classes (grades kindergarten through $6^{\text {th }}$ )." However, the potential for this error to confuse participants was reduced by the labeling of the question as "elementary school" and the listing of the grade range of kindergarten through $6^{\text {th }}$ grade. No participants reported confusion or asked for clarification on this item when completing the measure.

Attitudes toward social interactions. The MAS (Findler et al., 2007) is used to examine responses to a hypothetical person with a disability through the three domains of emotion, cognition, and behavior. Each domain is represented by a subscale and a total score is calculated through summing the average score on each subscale. The MAS is based on a short vignette in which a hypothetical person is placed in a situation in which the opportunity to interact socially with an unfamiliar person with a visible physical impairment is presented. The participant is 
asked to rate the likelihood that the hypothetical person will experience certain emotions and cognitions (i.e., thoughts) and engage in certain behaviors during the situation. The possible options include both positive (e.g., relaxation, calmness, serenity) and negative (e.g., guilty, upset, nervousness) emotions. All cognitions (i.e., items related to thoughts) are positive (e.g., $\mathrm{He} /$ she seems friendly). Behaviors include explicit avoidance behaviors (e.g., Get up and leave), more subtle avoidance behaviors (e.g., Read a newspaper or talk on a cell phone), and social engagement behaviors (e.g., Start a conversation).

Participants were asked to rate the likelihood of the hypothetical, able-bodied person engaging in each behavior, cognition, and emotion on a 5-point Likert-type scale, ranging from 1 (not at all) to 5 (very much). Positive emotions, positive cognitions, and social engagement behaviors were reverse-coded (i.e., high scores are reserved to represent low scores and vice versa). Both subscale scores (for the emotion, cognition, and behavior subscales) and total scores (summing the averages for each of the three subscale scores) can be calculated. Higher scores represent less positive attitudes toward people with disabilities.

The MAS questions and vignettes can be viewed in Findler et al. (2007). Only one change was made to the MAS for this study. Participants were not matched by gender to the character in the vignette; thus, both the male and female names were presented in the vignettes to both male and female participants.

MAS reading check. Four questions following the scale were used as a reading check to evaluate how much attention was paid to the vignette by the participant. The questions were on a different page from the vignette and the participant was instructed not to refer to the vignette when answering questions. For the 49 participants for whom reading check scores were available, six (12\%) answered a question incorrectly, suggesting that participants did read and remember the MAS vignette. The reading check questions and correct answers are in Appendix B.

Attitudes toward social inclusion. The Social Inclusion Scale (Hastings et al., 1998) is meant to assess the respondent's attitudes regarding whether people with disabilities should participate in ordinary life and leisure activities using autonomy of choice. Twenty-one of 22 items in the original scale were used for this study. One item ("Should be encouraged to use speech rather than sign language") was removed because it would not apply to all people with physical or sensory impairments. In addition, some language (e.g., "holiday" for "vacation") was changed to reflect linguistic differences between European and American English, and one item regarding dating was modified to be sexual-orientation neutral. Total scores were calculated by summing all items. The original 22 item scale showed good test-retest reliability $(r=.71)$ and high internal consistency (Cronbach's $\alpha=.87$; Hastings et al., 1998).

Hastings et al. (1998) initially tested the Social Inclusion Scale in two forms. It was piloted using the generic phrase, "People with [type of disability] disabilities..." to represent the subject. The revised version of the scale contained a short vignette about a person named Steven with a learning [intellectual] disability or speech impairment and used the phrase, "People like Steven..." (Hastings et al., 1998). For the sake of simplicity and to avoid participant fatigue caused by using two measures that required reading vignettes, the scale used in the present study had phrasing similar to that used in the Hastings et al. pilot study. The phrasing was modified to 
target the disability populations of interest in this study and read, "People with physical (examples include but are not limited to people who frequently use wheelchairs, walkers, crutches, canes, or similar devices, who are missing one or more limbs, and/or who have difficulty moving) or sensory impairments (blindness, deafness, or visual or hearing impairments)..."

The version of the Social Inclusion Scale used in the present study consisted of 21 items. Each item began with either "Should..." (e.g., "Should go to night-clubs") or "Should not..." (e.g., "Should not be told at what time to go"). Participants endorsed each item on a 5-point, Likerttype scale, with 1 representing "strongly disagree" and 5 representing "strongly agree" (Hastings et al., 1998). Possible scores ranged from 21-105, with higher scores representing a more positive attitude toward the community inclusion of people with disabilities. The original Social Inclusion Scale can be viewed in Hastings et al. (1998).

\section{Administration of Measures}

Upon arriving at the testing location, participants were given an informed consent form by a trained research assistant or the principal investigator and had the opportunity to ask questions about the consent form. After the participants gave informed consent, they were provided a packet consisting of the Disability Exposure Scale, MAS, and Social Inclusion Scale and asked to complete the measures in the packet to the best of their ability. If the participants responded yes to either of the exclusion questions (attended a non-American elementary or secondary school system or self-disclosed a disability), they were to speak to a research assistant who gave them the option to complete the packet or to leave at that time with full compensation.

\section{Results}

\section{Amount and Quality of Exposure}

All 50 participants had experienced some pre-college exposure to classmates with disabilities. Most students reported having at least one classmate with a physical or sensory impairment in their elementary school $(76 \%)$ or secondary school $(82 \%)$ classes. One-third $(32 \%)$ of the participants recalled having "several" classmates with physical or sensory impairments in elementary school; comparatively, half of the sample reported having "several" classmates with impairments in secondary school. Twenty-two and eighteen percent of participants reported having only classmates with non-physical or non-sensory disabilities at the elementary and secondary levels, respectively. In order to see whether coding exposure to only students with other (i.e., neither physical nor sensory) disabilities as low or no exposure affected the results, correlations were run with options coded as both 0 (i.e., as no exposure) and 2 (i.e., as low exposure). Both coding methods produced roughly the same results, suggesting that the attitude measures were primarily related to exposure to classmates with physical or sensory impairments specifically. Because of this lack of significant difference, we elected to treat exposure to students with other disabilities as "low exposure" when reporting the results. A paired sample $t$ test showed a significant difference between mean exposure scores at the elementary $(M=3.04$, $S D=.86)$ and secondary school $(M=3.32 ; S D=.87)$ levels $(t(49)=-2.447, p=.018)$. 
Similarly, participants also recalled high quality of exposure to their classmates with disabilities. At the elementary school level, 64\% of participants related having a "somewhat positive," "quite positive," or "extremely positive" experience with their classmates with disabilities, and 62\% reported positive experiences at the secondary school level. Comparatively, only $4 \%$ of participants described having "somewhat negative" experiences with classmates with disabilities at either the elementary or secondary school levels and none recalled a "quite negative" or "extremely negative" experience. A paired samples $t$-test revealed a significant difference between elementary $(M=2.02 ; S D=1.06)$ and secondary school $(M=2.38 ; S D=1.31)$ quality of exposure scores $(t(49)=-2.391, p=.021)$. Both scores were high, considering the possible range of -4 to 4 .

A series of bivariate correlations were run to assess the relationships between amount of exposure and quality of exposure. Amount of exposure was significantly correlated between elementary school and secondary school levels $(r=.508, p<.001)$. A similar relation was found for quality of exposure $(r=.613, p<.001)$.

\section{Psychometrics of Attitudes Measures}

Because both attitude measures (i.e., MAS and Social Inclusion Scale) were originally normed on populations outside the United States and were altered slightly to fit the aim and administration procedures of the present study, preliminary psychometrics were run to assess internal consistency. For the Social Inclusion Scale, internal consistency was high $(\alpha=.870)$, suggesting that the changes to wording made in the present study did not notably alter the items or the ways in which participants responded to them. The mean score on the Social Inclusion Scale was $91.5(S D=9.40$, range $=62-105)$, suggesting generally positive attitudes toward social inclusion of individuals with physical or sensory impairments among participants.

For the MAS, internal consistency was calculated for all three subscales as well as for the total scale. The emotion $(\alpha=.876)$, cognition $(\alpha=.892)$, and behavior $(\alpha=.792)$ subscales all demonstrated good to excellent internal consistency, as did the total scale $(\alpha=.879)$. Mean MAS scores for each of the subscales were as follows: emotion $(M=2.48, S D=.677)$; $\operatorname{cognition}(M=$ $2.38, S D=.718)$, and behavior $(M=2.32, S D=.657)$. These means were similar to those found in other studies using the MAS (e.g., Findler et al., 2007; Hein, Grumm, \& Fingerle, 2011). The MAS cognition subscale, while significantly correlated with the total MAS score $(r=.582, p$ $<.001)$, was not significantly correlated with either the emotion or behavior subscales. Conversely, the emotion and behavior subscales were significantly correlated with each other and with the total MAS score (see Table 1). When compared using a paired sample $t$-test, the mean scores for the emotion, behavior, and cognition subscales did not significantly differ from one another.

\section{Attitudes}

A negative correlation was found between amount of exposure at the elementary school level and Social Inclusion Scale scores $(r=-.312, p=.028)$, but this relationship did not hold when amount of exposure at the secondary school level was correlated with Social Inclusion Scale scores $(r=.019, p=.897)$. 
Total MAS scores were not significantly correlated with any level or quality of exposure. However, when the MAS score was broken down by subscale, the cognition subscale was significantly correlated with the quality of exposure at the elementary level $(r=-.434, p=.002)$ and secondary levels $(r=-.374, p=.008)$. In contrast, neither the emotion nor behavior subscales were significantly correlated with amount or quality of exposure at any level. Because a lower score on the MAS represents a more positive attitude toward people with disabilities, a negative correlation involving MAS scores represents a positive relationship between the other variable in the correlation and attitude.

Table 1

Relations Between Amount and Quality of Exposure and Attitudinal Measures

\begin{tabular}{|c|c|c|c|c|c|c|c|c|}
\hline & $\begin{array}{l}\text { Amount- } \\
\text { Elem }\end{array}$ & $\begin{array}{l}\text { Quality- } \\
\text { Elem }\end{array}$ & $\begin{array}{l}\text { Amount- } \\
\text { Second }\end{array}$ & $\begin{array}{l}\text { Quality- } \\
\text { Second }\end{array}$ & $\begin{array}{l}\text { Total } \\
\text { MAS }\end{array}$ & $\begin{array}{l}\text { MAS- } \\
\text { Cog }\end{array}$ & $\begin{array}{l}\text { MAS- } \\
\text { Emot }\end{array}$ & $\begin{array}{l}\text { MAS- } \\
\text { Behav }\end{array}$ \\
\hline $\begin{array}{l}\text { Quality- } \\
\text { Elem }\end{array}$ & -.136 & - & - & - & - & - & - & - \\
\hline $\begin{array}{l}\text { Amount- } \\
\text { Second }\end{array}$ & $.508^{* *}$ & .033 & - & - & - & - & - & - \\
\hline $\begin{array}{l}\text { Quality- } \\
\text { Second }\end{array}$ & .004 & $.613 * *$ & .039 & - & - & - & - & - \\
\hline $\begin{array}{l}\text { Total } \\
\text { MAS }\end{array}$ & .171 & -.253 & .166 & -.145 & - & - & - & - \\
\hline $\begin{array}{l}\text { MAS- } \\
\text { Cog }\end{array}$ & .055 & $-.434 * *$ & -.036 & $-.374 * *$ & $.582 * *$ & - & - & - \\
\hline $\begin{array}{l}\text { MAS- } \\
\text { Emot }\end{array}$ & .182 & -.057 & .214 & -.012 & $.712 * *$ & -.014 & - & - \\
\hline $\begin{array}{l}\text { MAS- } \\
\text { Behav }\end{array}$ & .123 & -.079 & .128 & .085 & $.806 * *$ & .186 & $.533 * *$ & - \\
\hline SIS & $-.312 *$ & .218 & .019 & .115 & .037 & -.096 & .041 & -.029 \\
\hline
\end{tabular}

Note. Elem $=$ elementary school; Second $=$ secondary school; MAS = Multidimensional Attitudes Scale; MAS-Cog $=$ MAS Cognition subscale; MAS-Emot $=$ MAS Emotion subscale , MAS-Behav = MAS Behavior subscale; SIS = Social Inclusion Scale; ${ }^{*} p<.05 ; * * p .01$. 


\section{Discussion}

This study assessed the relationship between exposure to students with disabilities in primary and secondary school with later attitudes toward people with disabilities. Although many factors may influence the development of attitudes toward people with disabilities over time, exposure during school represents a significant amount of time in a critical developmental context. Quality of exposure at the elementary and secondary level was positively correlated with more positive cognitions in a hypothetical encounter with a person with a disability. Amount of exposure at the elementary school level was negatively correlated with attitudes toward social inclusion, indicating that greater exposure to classmates with physical and sensory impairments in elementary school was actually associated with less positive attitudes towards the social inclusion of people with disabilities.

\section{Recalled Exposure}

Respondents reported a significantly greater exposure to classmates with disabilities in secondary school as compared to elementary school. This may be due to the fact that junior and senior high schools are often composed of students from several different elementary schools. Thus, this would reasonably lead to both a larger student body and a greater number of students with disabilities in the school. This difference might also be explained by the fact that, in the United States, elementary school students tend to stay in a single classroom all day with the same classmates, whereas secondary school students tend to rotate to multiple classrooms and courses throughout the day, thereby being exposed to a greater number and variety of students. Alternatively, it is possible that the education system itself may have become more inclusive over the 12 year period in which the participants were in elementary and secondary school, thus leading to greater exposure in secondary school.

Less time elapsed between the participants' experiences in secondary school and their participation in the study. Therefore, the greater recalled exposure during secondary school could be due, in part, to more accurate or more detailed recall for this time period, as compared to the elementary grades. This time difference could also affect recollections of quality of exposure in a similar manner.

The participants' generally positive recollections of their interactions with students with disabilities should also be noted. Only two participants referenced any type of negative recalled experience with classmates with disabilities, suggesting that a vast majority of the students did not feel negatively affected by the presence of students with disabilities, especially students with physical or sensory impairments, in their elementary and secondary school classes. Although it is possible that these responses were influenced by social desirability bias (i.e., the perceived social pressure to report positive attitudes toward individuals with disabilities), the anonymous nature of the questionnaire and the fact that the measure was asking specifically about interactions that occurred with anonymous people in the past may have decreased the impact of social desirability bias.

One of the strengths of this study was the fact that data on subjective quality of exposure, not solely exposure, were collected. Additionally, this study did not assume that being in an inclusive 
school equaled exposure in and of itself, but asked participants to recall whether there were students with disabilities in their particular classes, not just in the school as a whole.

\section{Attitudinal Measures}

Social inclusion. Perhaps one of the most surprising results of this study was the negative correlation between amount of exposure to students with physical or sensory impairments at the elementary school level and later attitudes toward social inclusion. It is possible that participants with greater exposure to young children with disabilities may have been thinking of those encounters as a reference while completing the Social Inclusion Scale and thus may have been less likely to strongly endorse items related to independence and autonomy (i.e., "Should not be told when to go to bed"). This idea was further supported by the fact that some participants spontaneously wrote qualifying statements such as "It depends how old they are" next to some questions on the Social Inclusion Scale. In future studies, it may be beneficial to include a distinct stage of life or age range as a cognitive guide for participants or to query participants about different age ranges separately.

Social interactions. The use of the MAS, which uses a specific hypothetical encounter rather than general statements of opinion, may have helped to reduce the impact on social desirability bias on responses; this is notable as social desirability bias can be a barrier to accurately measuring attitudes toward disability (Pruett \& Chan, 2006).

The subscale correlations in this study did not confirm those of the original MAS development study by Findler and colleagues (2007). Although both studies found that emotion and behavior were the two most highly correlated subscales, Findler et al. also found a significant positive correlation between the emotion and behavior subscales and the cognition subscale; the present study did not. This may point to possible cultural differences between the two samples, as Findler and colleagues' study used an English-speaking Israeli population whereas the sample in this study consisted of English-speaking American students, such as different social norms for behavior.

The findings also suggest that exposure to and interaction with students with disabilities only correlated with participants' thoughts during a hypothetical interaction with a person with disability, but not with their emotions or behaviors during that same encounter. Furthermore, cognitions were not shown to be related to either emotions or behaviors, suggesting that what people think when meeting a person with a physical impairment may not be representative of either how they feel or act toward that person in the same encounter. Future studies should examine the MAS subscales using vignettes involving hypothetical encounters with people with and without disabilities in order to better understand the impact of the hypothetical person's impairment on participant responses.

The significant correlations between quality of exposure at both the elementary and secondary levels and more positive cognitions toward a hypothetical person with a disability suggested that having positive experiences with classmates with disabilities may have a significant impact on how students regard people with disabilities later in life. The items on the cognitive subscale of the MAS are not only positive (e.g., "He/she looks friendly") but also emphasized viewing the 
person with a disability in a way that implies that the person with a disability is a potential friend (e.g., "We may get along really well."). Thus, having high quality experiences with people with physical and sensory disabilities in childhood and adolescence may make a young adult more likely to view people with physical disabilities, like the hypothetical acquaintance in the MAS vignette, as potential friends and companions.

\section{Limitations and Future Research}

The primary limitation of this study was its small sample size $(n=49)$. In addition to the lower overall power, the relatively high number of correlations and $t$-tests run increased the probability of a false positive (i.e., falsely significant) result due to chance (Thompson, 2006). Because of this, a Sidak or Bonferroni correction might be used to reduce the target $p$-value to $p=.000$ or less ( $p=.000$ is the lowest $p$-value reported by SPSS) and thus reduce the probability of reporting a false positive result (Thompson, 2006). Due to this study's status as a pilot study, all results that were significant at the $p<.05$ level were reported. However, results that are significant at a level above $p<.001$ should be interpreted with caution.

Secondly, this study required current college students to recall the presence of students with physical or sensory impairments in their classes from the age of five onward. This required recall from between 13 and 33 years in the past and it is possible that participants may have unintentionally misrepresented their levels of exposure. Memories tend to fade and become less reliable over time and thus participants may have over- or under-reported their actual exposure to classmates with physical or sensory impairments. Finally, it is possible that the typographical error in the exposure measure may have led to some confusion among participants; however, no participants indicated confusion verbally or on the questionnaire.

It is also possible that the broad response categories (e.g., "several," "one or two") may have unintentionally obscured some of the effects of different levels of exposure and that social desirability may have influenced responses, especially in cases where, due to unexpected scheduling conflicts, the principal investigator-who has a visible physical disability - had to administer the questionnaires. However, the standard deviations for MAS subscales were similar to those found in other studies of the MAS ( $S D=.66-.72$ compared to $.41-70$ in Hein et al., 2011 and $.62-.70$ in Findler et al., 2007). Thus, it appears unlikely that a subset of participants in this sample gave markedly more positive responses due to who administered their questionnaire.

It is possible that the long-term effects of exposure may not be the same across disability types. This may be an effect of cognitive schemas regarding the definition of "disability;" people who have exposure to only classmates with invisible disabilities may not apply their past experiences to an encounter with a person in a wheelchair as readily as those people with past experience with classmates with more visually apparent disabilities, as in the MAS vignette. Future research should expand this research by examining other types of disability, both in terms of exposure and with different MAS vignettes.

An additional weakness of this study is that data regarding exposure to people with disabilities other than classmates were not collected. Although the effects of community-based exposure on 
attitudes toward people with disabilities is somewhat unclear (see Finch, 1998; Laws \& Kelly, 2005), it is possible that some of the participants may have had interactions with people with disabilities outside of their classes (e.g., family members, friends) that significantly influenced their attitudes. Future research, especially with resources to obtain a larger sample size, should examine these non-school-based interactions with people with disabilities as a potential mediating factor.

\section{Conclusion}

It is notable that all participants in this study reported having at least one classmate with a noticeable disability in their classes during elementary or secondary school. This suggests that the current generation of college students received some exposure to classmates with disabilities, likely as a result of inclusionary education practices under federal law (e.g., IDEA, 2004). It appears that the push for the integration of students with disabilities is being noticed by their general education classmates. Furthermore, the participants reported generally positive experiences with their classmates with disabilities, indicating that they did not see the effects of inclusion as detrimental. Although this is a small, preliminary study, the results do tentatively indicate that inclusion, including inclusion of children with sensory and physical impairments, has led to greater exposure to classmates with physical and sensory impairments among current young adults.

\section{References}

Cameron, L., Rutland, A. \& Brown, R. J. (2007). Promoting children's positive intergroup attitudes towards stigmatized groups: Extended contact and multiple classification skills training. International Journal of Behavioral Development, 31, 454-466. http://dx.doi.org/10.1177/0165025407081474

Diamond, K. E., \& Hestenes, L. L. (1996). Preschool children's conceptions of disabilities: The salience of disability in children's ideas about others. Topics in Early Childhood Special Education, 16, 458-475. http://dx.doi.org/10.1177/027112149601600406

Fisher, D., Pumpian, I., \& Sax C. (1998). High school students' attitudes about and recommendations for their peers with significant disabilities. Journal of the Association for Persons with Severe Handicaps, 23, 272-282. http://dx.doi.org/10.2511/rpsd.23.3.272

Finch, J. G. (1998). Attitudes of children without disabilities toward peers with disabilities: The effect of contact in a summer camp program. (Unpublished doctoral dissertation). Temple University, Philadelphia, PA. Abstract retrieved from ProQuest Digital Dissertation Database.

Findler, L., Vilchinsky, N., \& Werner, S. (2007). The Multidimensional Attitudes Scale toward persons with disabilities (MAS): Construction and validation. Rehabilitation Counseling Bulletin, 50, 166-176. http://dx.doi.org/10.1177/00343552070500030401 
Hastings, R., Sjöström, K. \& Stevenage, S. (1998). Swedish and English adolescents' attitudes toward the community presence of people with disabilities. Journal of Intellectual Disability Research, 42, 246-253. http://dx.doi.org/10.1046/j.1365-2788.1998.00125.x

Hein, S., Grumm, M., \& Fingerle, M. (2011). Is contact with people with disabilities a guarantee for positive implicit and explicit attitudes? European Journal of Special Needs Education, 26, 509-522. http://dx.doi.org/10.1080/08856257.2011.597192

Kishi, G. S. \& Meyer, L. H. (1994). What children report and remember: A 6-year follow-up of the effects of the social contact between peers with and without severe disabilities. Journal of the Association for Persons with Severe Handicaps, 19, 277-289.

Individuals with Disabilities Education Improvement Act. (2004). Public Law § 108-446 (20 U.S.C. $\S 1400$ et seq.)

Laws, G. \& Kelly, E. (2005). The attitudes and friendship intentions of children in United Kingdom mainstream schools towards peers with physical or intellectual disabilities. International Journal of Disability, Development and Education, 52, 79-99. http://dx.doi.org/10.1080/10349120500086298

Pruett, S. R. \& Chan, F. (2006). The development and psychometric validation of the Disability Attitude Implicit Association Test. Rehabilitation Psychology, 51, 202-213. http://dx.doi.org/10.1037/0090-5550.51.3.202

Thompson, B. (2006). Foundations of behavioral statistics: An insight-based approach. New York: Guilford.

United States Department of Education (n.d.). Questions and answers on least restrictive environment (LRE) requirements of the IDEA. Wright's Law. Retrieved from http://www.wrightslaw.com/info/lre.osers.memo.idea.htm

Wong, D. P. K (2008). Do contacts make a difference? The effects of mainstreaming on student attitudes toward people with disabilities. Research in Developmental Disabilities, 29(1), 70-82. http://dx.doi.org/10.1016/j.ridd.2006.11.002

Authors' note: The authors would like to thank Madison Langston, Kayla Blackman, and Brandi Keeney for their assistance with data collection; Paul Silverman, Rosemary B. Hughes, and Gregory Machek for their assistance with conceptualization; and Catherine Lund for her assistance with administrative tasks. Address correspondence concerning this article to Emily Lund, MEd at emily.m.lund@gmail.com or emily.lund@ aggiemail.usu.edu. 


\section{Appendix A}

Disability Exposure Scale

This instrument asks you to report on the level of exposure to students with disabilities and the quality of your interactions with them during your primary and secondary education. Please answer the questions below to the best of your ability.

\section{Questions}

1. a. Elementary School Years Were there any students with physical (examples include but are not limited to students who frequently used wheelchairs, walkers, crutches, canes, or similar devices, who were missing one or more limbs, and/or who had difficulty moving) or sensory impairments (blindness, deafness, or visual or hearing impairments) in your junior high school classes (grades kindergarten through $6^{\text {th }}$ )?

( ) Yes, several

( ) Yes, one or two

( ) No, but there were students with other disabilities (i.e., mental illness, autism, emotional or behavioral difficulties, intellectual disabilities, dyslexia or other learning disabilities, etc.)

( ) No, to my knowledge, there were no students with disabilities

( ) Do not recall.

b. In general, do you remember your interactions with or exposure to students with disabilities to be (circle one):

\begin{tabular}{|c|c|c|c|c|c|c|c|}
\hline $\begin{array}{c}\text { Extremely } \\
\text { positive }\end{array}$ & $\begin{array}{c}\text { Quite } \\
\text { positive }\end{array}$ & $\begin{array}{c}\text { Somewhat } \\
\text { positive }\end{array}$ & Neutral & $\begin{array}{c}\text { Somewhat } \\
\text { negative }\end{array}$ & $\begin{array}{c}\text { Quite } \\
\text { negative }\end{array}$ & $\begin{array}{c}\text { Extremely } \\
\text { negative }\end{array}$ & $\begin{array}{c}\text { Not } \\
\text { applicable }\end{array}$ \\
\hline
\end{tabular}

2. a. Junior High and High School Years Were there any students with physical (examples include but are not limited to students who frequently used wheelchairs, walkers, crutches, canes, or similar devices, who were missing one or more limbs, and/or who had difficulty moving) or sensory impairments (blindness, deafness, or visual or hearing impairments) in your junior high or high school classes (grades $\left.7^{\text {th }}-12^{\text {th }}\right)$ ?

( ) Yes, several

() Yes, one or two

( ) No, but there were students with other disabilities (i.e., mental illness, autism, emotional or behavioral difficulties, intellectual disabilities, dyslexia or other learning disabilities, etc.)

( ) No, to my knowledge, there were no students with disabilities

( ) Do not recall

b. In general, do you remember your interactions with or exposure to students with disabilities to be ... (circle one):

\begin{tabular}{|c|c|c|c|c|c|c|c|}
\hline $\begin{array}{c}\text { Extremely } \\
\text { positive }\end{array}$ & $\begin{array}{c}\text { Quite } \\
\text { positive }\end{array}$ & $\begin{array}{c}\text { Somewhat } \\
\text { positive }\end{array}$ & Neutral & $\begin{array}{c}\text { Somewhat } \\
\text { negative }\end{array}$ & $\begin{array}{c}\text { Quite } \\
\text { negative }\end{array}$ & $\begin{array}{c}\text { Extremely } \\
\text { negative }\end{array}$ & $\begin{array}{c}\text { Not } \\
\text { applicable }\end{array}$ \\
\hline
\end{tabular}




\section{Appendix B}

MAS Reading Check Questions

The follow questions concern the vignette you just read about Joseph/Michelle. Please answer the following questions to the best of your ability. Do not refer back to the vignette!

1. Joseph/Michelle is:

a. In a coffee shop

b. In a hospital

c. In a person's home

(Correct answer: a)

2. Based on the vignette, the person Joseph/Michelle meets:

a. Is blind

b. Is deaf

c. Uses a wheelchair

(Correct answer: $c$ )

3. Joseph/Michelle and the person with a disability are:

a. Left alone at the table

b. Always with other people

c. Good friends

(Correct answer: a)

4. Joseph/Michelle and the person with a disability are together for

a. 2 hours

b. 15 minutes

c. 45 minutes

(Correct answer: $b$ ) 